\title{
DESIDROGENAÇÃO DO ETILBENZENO SOBRE COMPOSTOS DE FERRO E ALUMÍNIO
}

\author{
Alcinéia Conceição Oliveira e Maria do Carmo Rangel* \\ Instituto de Química, Universidade Federal da Bahia, Campus Universitário de Ondina, 40170-290 Salvador- BA
}

Recebido em 30/1/02; aceito em 11/7/02

\begin{abstract}
DEHYDROGENATION OF ETHYLBENZENE OVER IRON AND ALUMINUM COMPOUNDS. Chromium and potassium-doped iron oxides are widely used as industrial catalysts in the dehydrogenation of ethylbenzene to produce styrene. They have several advantages but deactivate with time, because of the loss of potassium. Also, they are toxic due to chromium compounds. Therefore there is a need for developing alternative non toxic catalysts without potassium. Then, iron and aluminum compounds were prepared by different methods in this work. Different phases were produced depending on the preparation method. Aluminum-doped hematite was more active and selective to styrene than the aluminum ferrite. Aluminum acts both as textural and structural promoter in the catalysts.
\end{abstract}

Keywords: ethylbenzene dehydrogenation; aluminum ferrite; hematite.

\section{INTRODUÇÃO}

O monômero estireno é um dos intermediários químicos mais valiosos e mais utilizados em sínteses orgânicas, devido ao seu emprego como matéria-prima na produção de borrachas sintéticas, plásticos e resinas copoliméricas ${ }^{1-3}$. Cerca de três milhões de toneladas de estireno são produzidas por ano na Ásia, quinze bilhões de toneladas na Europa e oito bilhões de toneladas na América. Diversas vias de obtenção desse produto podem ser empregadas, tanto nas indústrias, como em laboratório, destacando-se a desidrogenação oxidativa do etilbenzeno, a alquilação do metanol, a dimerização do estireno, seguida de desproporcionamento e degradação do próprio poliestireno reciclado, dentre outros ${ }^{4-7}$. Recentemente, processos industriais que utilizam catalisadores à base de óxidos de ferro, em forma de colméia, têm sido amplamente utilizados, e a produção de estireno a partir desses processos atinge vinte milhões de toneladas por ano ${ }^{8}$

A rota comercial mais empregada para a produção do estireno, desde a implementação do primeiro processo industrial em 1930, é a desidrogenação catalítica do etilbenzeno em presença de vapor d'água ${ }^{9}$. O processo envolve a reação principal $^{1}$

$\mathrm{C}_{6} \mathrm{H}_{5}-\mathrm{CH}_{2} \mathrm{CH}_{3(\mathrm{~g})} \stackrel{\mathrm{H}_{2} \mathrm{O}_{(\mathrm{g})}}{\rightleftarrows} \mathrm{C}_{6} \mathrm{H}_{5}-\mathrm{CH}=\mathrm{CH}_{2(\mathrm{~g})}+\mathrm{H}_{2(\mathrm{~g})} \quad \Delta \mathrm{H}=121 \mathrm{~kJ} \cdot \mathrm{mol}^{-1}$

mas podem ocorrer reações secundárias ${ }^{1}$

$$
\begin{aligned}
& \mathrm{C}_{6} \mathrm{H}_{5}-\mathrm{CH}_{2} \mathrm{CH}_{3(\mathrm{~g})} \rightleftarrows \mathrm{C}_{6} \mathrm{H}_{5}-\mathrm{H}_{(\mathrm{g})}+\mathrm{C}_{2} \mathrm{H}_{4(\mathrm{~g})} \\
& \mathrm{C}_{6} \mathrm{H}_{5}-\mathrm{CH}_{2} \mathrm{CH}_{3(\mathrm{~g})}+\mathrm{H}_{2(\mathrm{~g})} \rightleftarrows \mathrm{C}_{6} \mathrm{H}_{5}-\mathrm{CH}_{3(\mathrm{~g})}+\mathrm{CH}_{4(\mathrm{~g})} \\
& \mathrm{C}_{6} \mathrm{H}_{5}-\mathrm{CH}_{2} \mathrm{CH}_{3(\mathrm{~g})} \longrightarrow \text { coque }+\mathrm{H}_{2(\mathrm{~g})} \\
& \text { coque }+\mathrm{H}_{2} \mathrm{O}_{(\mathrm{g})} \longrightarrow \mathrm{x} \mathrm{CO}_{2(\mathrm{~g})}+\mathrm{y} \mathrm{H}_{2(\mathrm{~g})}
\end{aligned}
$$

principalmente a formação de coque, que prejudicam o rendimento da reação e danificam o catalisador ${ }^{10,11}$. Desta forma, o processo é conduzido em presença de excesso de vapor, que oxida os depósitos

\footnotetext{
*e-mail: mcarmov@ufba.br
}

de carbono, supre o calor necessário à reação e desloca o equilíbrio químico, aumentando a produção de estireno ${ }^{1,9}$.

Os catalisadores mais empregados, na desidrogenação do etilbenzeno com vapor d'água, são óxidos inorgânicos, em particular óxidos de ferro (hematita) contendo diversos promotores, entre os quais os principais são óxidos de potássio, de cromo e de cério ${ }^{11}$. Esses catalisadores apresentam a vantagem do baixo custo, mas sofrem rápida desativação ao longo de sua vida útil, devido à perda de potássio que migra para a saída do reator e é arrastado pela corrente gasosa $^{12}$. Diversas melhorias já foram introduzidas no catalisador e no processo, mas muitos dos problemas da reação, como o alto consumo de energia, baixa conversão, depósito de coque e toxicidade do catalisador ainda não foram solucionados ${ }^{13-15}$.

Neste contexto, estudou-se o desenvolvimento de catalisadores alternativos, à base de compostos de ferro e alumínio, destinados à desidrogenação do etilbenzeno com vapor d'água, a fim de se obter catalisadores isentos de potássio e que sejam mais ativos, seletivos e resistentes à desativação, além de poderem ser descartados sem causar danos ao homem e ao meio ambiente. Foram estudados catalisadores à base de ferrita de alumínio e de hematita $\left(\alpha-\mathrm{Fe}_{2} \mathrm{O}_{3}\right)$ contendo alumínio. As ferritas são óxidos com estrutura de espinélio constituídos por átomos de oxigênio, num arranjo cúbico densamente empacotado, que formam posições octaédricas ocupadas por átomos de ferro $^{16}$. Esses materiais apresentam propriedades magnéticas e catalíticas que os tornam atrativos para diversas aplicações e seu estudo tem atraído considerável atenção, nos últimos anos ${ }^{12,17-19}$. Apesar disso, poucas ferritas, nas quais o ferro foi substituído por cátions trivalentes, foram preparadas e estudadas ${ }^{20,21}$. Em outros trabalhos, observou-se que diversos óxidos com estruturas de espinélios são catalisadores promissores para a desidrogenação do etilbenzeno, mas não foram conduzidos estudos detalhados no que se refere à ferrita de alumínio $^{22,23}$.

Por outro lado, a hematita apresenta estrutura romboédrica, em que os íons $\mathrm{O}^{2-}$ formam um retículo hexagonal compacto, com 2/3 dos interstícios octaédricos ocupados pelos íons $\mathrm{Fe}^{3+}$ em camadas alternativas (estrutura do corundum ${ }^{24}$. A proximidade entre os raios atômicos das espécies $\mathrm{Fe}^{3+}$ e $\mathrm{Al}^{3+}$ levam à substituição frequiente do primeiro pelo segundo na rede da hematita. Este óxido encontra muitas aplicações como catalisador ou como precursor de catalisador e constitui a fase ativa dos catalisadores comerciais destinados à 
desidrogenação do etilbenzeno, em presença de vapor d'água, den-

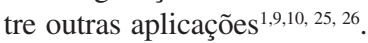

\section{PARTE EXPERIMENTAL}

O catalisador à base de hematita foi obtido por hidrólise simultânea de nitrato de ferro e nitrato de alumínio $(\mathrm{Fe} / \mathrm{Al}($ molar $)=1)$, com solução $25 \%$ de hidróxido de amônio. Após a adição dos reagentes, a solução foi mantida sob agitação por $30 \mathrm{~min}$, à temperatura ambiente e o pH final foi ajustado para 11. Em seguida, a solução coloidal foi centrifugada e o gel obtido foi lavado com água para a remoção do ânion do material de partida, pois este pode influenciar as características e a atividade catalítica da hematita ${ }^{27}$. As etapas de lavagem e centrifugação foram repetidas até se completar um total de seis lavagens, para garantir a completa remoção dos íons nitrato provenientes do material de partida ${ }^{26}$. Após a sétima centrifugação, o gel foi seco a $120^{\circ} \mathrm{C}$ por $12 \mathrm{~h}$, moído e peneirado em 100 mesh, obtendo-se o precursor do catalisador. O sólido foi calcinado sob fluxo de nitrogênio $(60 \mathrm{~mL} / \mathrm{min})$ a $700{ }^{\circ} \mathrm{C}$ por $2 \mathrm{~h}$, obtendo-se a Amostra FA1. Este procedimento foi designado como Método 1 . Foram também preparadas amostras de óxido de ferro (Amostra F) e óxido de alumínio (Amostra A) puros, usando o mesmo procedimento experimental, que foram usadas como referências.

Uma outra amostra, à base de ferrita de alumínio, foi preparada usando o método proposto por Jebarathinan e colaboradores ${ }^{28}$ (Amostra FA2). Uma solução contendo nitrato de ferro e de alumínio (Fe/ $\mathrm{Al}$ (molar)=1), foi aquecida a $60{ }^{\circ} \mathrm{C}$ e, a esta, foi adicionada (ainda quente) uma solução de hidróxido de amônio 5\%, gota a gota, sob agitação constante, mantendo-se o pH em 6,2. Em seguida, a mistura foi aquecida por $2 \mathrm{~h}$, a $80{ }^{\circ} \mathrm{C}$ e o precipitado foi separado por filtração, lavado, seco em estufa a $120^{\circ} \mathrm{C}$, por $12 \mathrm{~h}$ e calcinado sob fluxo de nitrogênio $(60 \mathrm{ml} / \mathrm{min})$ à temperatura de $800^{\circ} \mathrm{C}$ (Método 2).

Os precursores dos catalisadores foram caracterizados por análise térmica (DSC, TG), para se avaliar a influência das variáveis sob estudo sobre a formação do catalisador, e por espectroscopia no infravermelho com transformadas de Fourier (FTIR) para verificar a presença do íon nitrato nos sólidos.

Os catalisadores foram caracterizados por análise química, medida de área superficial específica (método BET), redução à temperatura programada (TPR) e difração de raios X (DRX).

Os teores de ferro e alumínio foram determinados através de um espectrômetro de emissão atômica em plasma indutivamente acoplado (ICP/AES) seqüencial, marca ARL, modelo 3410 com minitocha. Nestas análises, cerca de $0,1 \mathrm{~g}$ da amostra foi dissolvido em $15 \mathrm{~mL}$ de ácido nítrico concentrado, evaporado à quase secura e retomado a $100 \mathrm{~mL}$ de ácido clorídrico 1\%, em balão volumétrico.

As medidas de área superficial específica, bem como os experimentos de redução à temperatura programada, foram realizadas em um aparelho Micromeritics, modelo TPD/TPO 2900. Nas medidas de área, usou-se uma massa de cerca de $0,15 \mathrm{~g}$ acondicionada em uma cela de vidro, que foi aquecida sob fluxo de nitrogênio $(60 \mathrm{~mL} /$ $\min$ ) até $160^{\circ} \mathrm{C}$. A amostra permaneceu nesta temperatura durante $1 \mathrm{~h}$ e, em seguida, foi analisada utilizando uma mistura $30 \% \mathrm{~N}_{2} / \mathrm{He}$ ( $60 \mathrm{ml} / \mathrm{min}$ ). Nos experimentos de TPR, uma massa de cerca de $0,35 \mathrm{~g}$ foi submetida a um aquecimento programado (10 graus $/ \mathrm{min}$ ), acompanhando-se o consumo de hidrogênio de uma mistura $5 \% \mathrm{H}_{2} / \mathrm{N}_{2}$, numa faixa de temperatura de 30 a $1000^{\circ} \mathrm{C}$.

Os experimentos de calorimetria diferencial de varredura (DSC) e termogravimetria (TG) foram conduzidos em aparelhos Shimadzu DSC e TG 50, respectivamente, sob fluxo de nitrogênio, até $600{ }^{\circ} \mathrm{C}$ (no caso do DSC) e $1000{ }^{\circ} \mathrm{C}$ (no caso do TG).

As análises de espectroscopia de absorção na região do infravermelho com transformadas de Fourier (FTIR) foram realiza- das em um aparelho Shimadzu Spectra IV, na faixa de 4000 a 400 $\mathrm{cm}^{-1}$, usando pastilhas das amostras diluídas em brometo de potássio.

Os difratogramas de raios $\mathrm{X}$ foram obtidos através do equipamento Shimadzu, modelo XD3A, usando-se radiação $\mathrm{CuKa}$, gerada a $30 \mathrm{kV}$ e $20 \mathrm{~mA}$ e filtro de níquel. As amostras foram moídas num almofariz de ágata e, em seguida, acondicionadas no porta-amostra.

Os catalisadores foram avaliados em teste microcatalítico a $530^{\circ} \mathrm{C}$ e 1 atm de pressão. Utilizou-se uma razão molar vapor d'água/ etilbenzeno $=10$ e $0,3 \mathrm{~g}$ de amostra. $\mathrm{O}$ reator, contendo o catalisador, foi aquecido, sob fluxo de nitrogênio $(60 \mathrm{ml} / \mathrm{min})$ até à temperatura da reação. Em seguida, interrompeu-se a alimentação de nitrogênio e introduziu-se a mistura gasosa reacional. Esta mistura foi obtida passando-se uma corrente de nitrogênio por um saturador contendo etilbenzeno e, em seguida, por uma câmara de mistura onde também foi alimentado vapor d'água. A corrente gasosa, assim formada, foi introduzida no reator, iniciando-se a reação. O efluente do reator foi recolhido em condensador e a fase orgânica foi analisada por cromatografia gasosa, num aparelho CG-37, munido de uma coluna carbowax 5\% em cromosorb e um detetor de ionização de chama. Para fins de comparação, foi medida também a atividade e a seletividade de um catalisador comercial.

\section{RESULTADOS E DISCUSSÃO}

Os resultados de análise química (Tabela 1) mostraram razões molares $\mathrm{Fe} / \mathrm{Al}$ superiores aos valores de partida, indicando que a formação dos compostos de ferro foi favorecida em relação à dos compostos de alumínio. Isto pode ser atribuído à cinética lenta de formação dos últimos em relação aos primeiros. A cinética de hidrólise

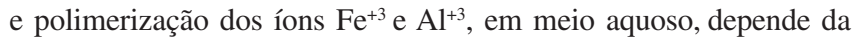
labilidade das espécies formadas, em relação à substituição nucleofílica, que depende da carga, tamanho, eletronegatividade, e configuração eletrônica do átomo ${ }^{29}$. Quanto menor a carga e maior o raio iônico, mais rapidamente a ligação metal-ligante será rompida . Portanto, em meio aquoso, os íons $\mathrm{Al}^{+3}$ formarão espécies mais inertes que o $\mathrm{Fe}^{+3}$, que possui um raio iônico maior. Em concordância com estas conclusões, o íon $\mathrm{Fe}^{+3}$ possui uma constante de hidrólise de $6,7 \times 10^{-3} \mathrm{~s}^{-1}$ enquanto o íon $\mathrm{Al}^{+3}$ possui o valor de $9,55 \times 10^{-6} \mathrm{~s}^{-1} 30,31$.

Tabela 1. Análise química dos catalisadores obtidos. Amostra F: óxido de ferro; Amostra A: alumina. Amostras FA1 e FA2: compostos de ferro e alumínio obtidos pelos Métodos 1 e 2, respectivamente

\begin{tabular}{lccc}
\hline Amostra & $\% \mathrm{Fe}( \pm 0,2)$ & $\% \mathrm{Al}( \pm 0,2)$ & $\mathrm{Fe} / \mathrm{Al}($ molar $)$ \\
\hline F & 71,82 & - & - \\
Al & - & 76,86 & - \\
FA1 & 12,93 & 8,32 & 1,6 \\
FA2 & 14,37 & 7,24 & 1,9 \\
\hline
\end{tabular}

Os espectros de FTIR dos precursores do óxido de ferro puro (Amostra F) e do material obtido pelo Método 1 (Amostra FA1) mostraram bandas características da espécie nitrato $\left(1385 \mathrm{~cm}^{-1}\right)$, além da banda de absorção larga, abaixo de $800 \mathrm{~cm}^{-1}$, atribuída à vibração de estiramento da ligação $\mathrm{Fe}-\mathrm{O}{ }^{32}$. Após a calcinação, as bandas de absorção devido ao ânion nitrato desapareceram, indicando a eliminação desta espécie do sólido, como mostra a Figura 1. A banda devida à ligação $\mathrm{Fe}-\mathrm{O}$, tornou-se mais estreita, como conseqüência da cristalização do óxido de ferro $^{33}$. Esses resultados estão de acordo com trabalhos da literatura, segundo os quais o íon nitrato pode ser completamente eliminado a temperaturas elevadas ${ }^{33}$. 


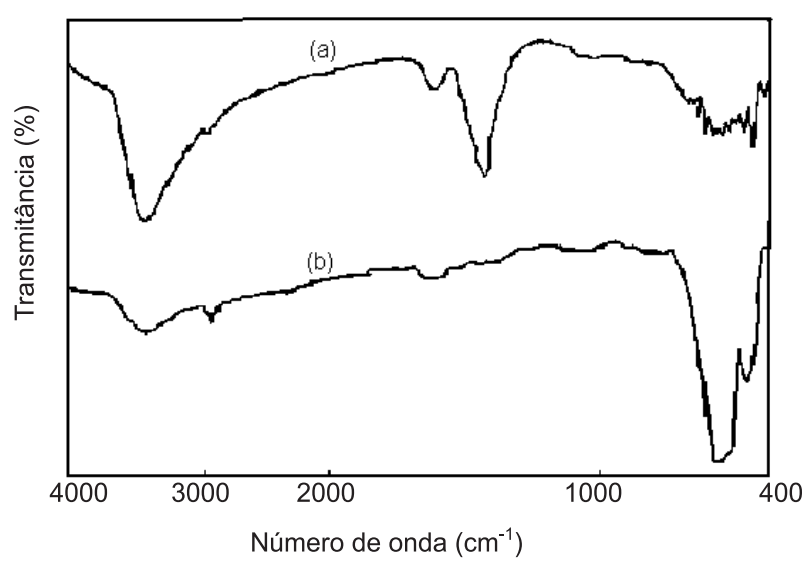

Figura 1. Espectros de FTIR dos precursores (a) e dos catalisadores (b) Amostra F: composto de ferro; Amostra FA1: composto de ferro e alumínio com razão molar Fe/Al= 1

O material contendo apenas alumínio (Amostra A) apresentou espectro de FTIR com bandas de absorção a 3000 e $2555 \mathrm{~cm}^{-1}$, atribuídas ao estiramento simétrico e assimétrico da ligação $\mathrm{OH}$ da água, respectivamente ${ }^{34}$, e uma banda de absorção a $1385 \mathrm{~cm}^{-1}$, devido à espécie nitrato ${ }^{35}$. Esta última banda desapareceu quando a amostra foi calcinada a $700{ }^{\circ} \mathrm{C}$, indicando que esta temperatura é adequada para a remoção desse ânion do sólido, como mostra a Figura 2.

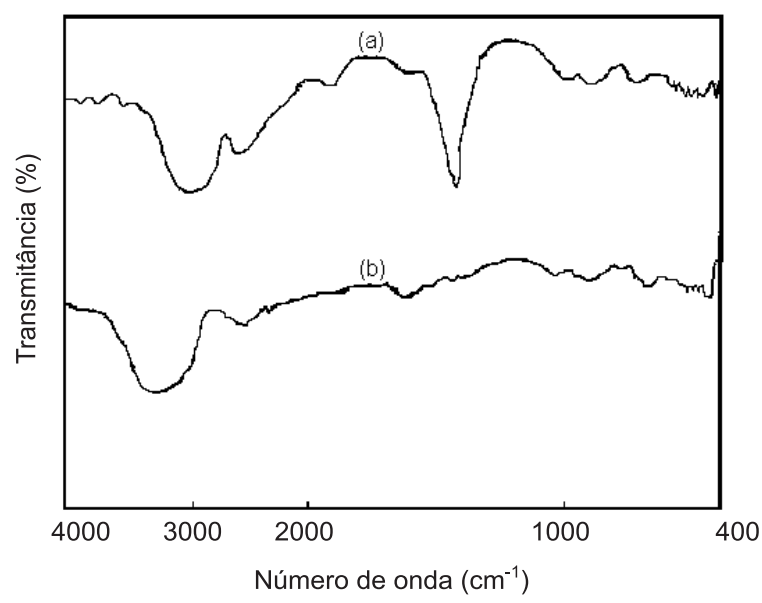

Figura 2. Espectros de FTIR da alumina (A) pura antes (a) e após a calcinação

O espectro de FTIR da Amostra FA2 (Figura 3) mostrou bandas características das ferritas em 3745, 3660 e $700 \mathrm{~cm}^{-1}$, relacionadas ao grupo $\mathrm{OH}$ da superfície terminal, tetraedricamente coordenada à espécie $\mathrm{Fe}^{+336}$. Após a calcinação, estas bandas desapareceram, confirmando informações anteriores de que a temperatura de $800{ }^{\circ} \mathrm{C}$ é eficiente para a remoção de tais espécies ${ }^{37}$.

A Figura 4 mostra o padrão de difração dos catalisadores novos e a Tabela 2 mostra as distâncias interplanares calculadas. Observou-se a presença de hematita $\left(\alpha-\mathrm{Fe}_{2} \mathrm{O}_{3}\right)$, nos catalisadores preparados pelo Método 1 (Amostra FA1) e no óxido de ferro sem dopante (Amostra F). O material contendo apenas alumínio (Amostra A) apresentou difratograma típico da $\gamma$-alumina. A Amostra FA2 foi identificada como sendo uma ferrita de alumínio do tipo $\mathrm{Al}_{0,1} \mathrm{Fe}_{1,9} \mathrm{O}_{4}$.

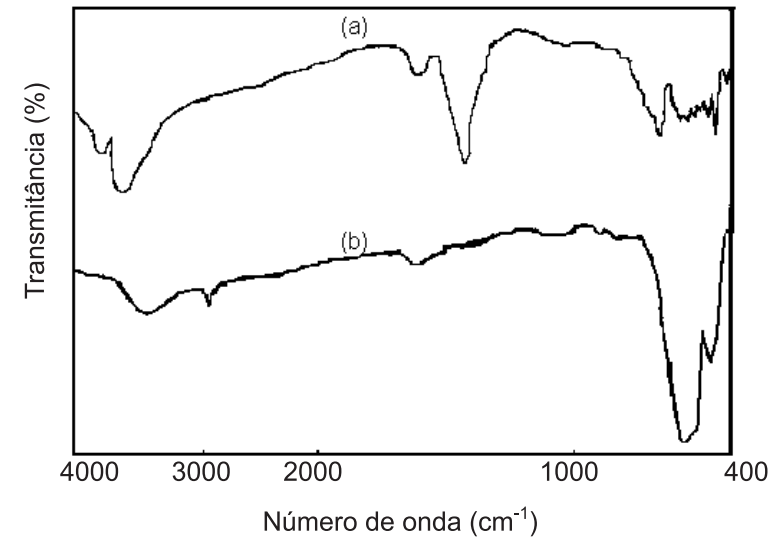

Figura 3. Espectro de FTIR do composto de ferro e alumínio com razão molar Fe/Al= 2 (Amostra FA2) antes (a) e após a calcinação (b)

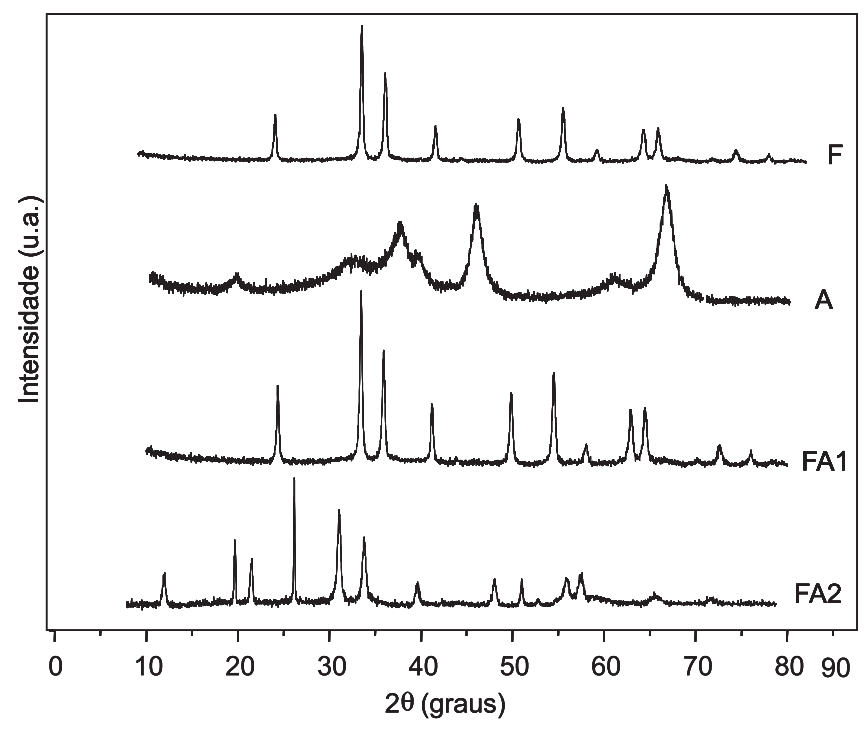

Figura 4. Difratogramas de raios $X$ dos catalisadores novos. Amostra A: alumina; Amostra F: óxido de ferro; Amostras FA1 e FA2: hematita contendo alumínio e ferrita de alumínio, respectivamente

Durante a desidrogenação do etilbenzeno, estes materiais sofreram mudança de fase de hematita para magnetita $\left(\mathrm{Fe}_{3} \mathrm{O}_{4}\right)$, exceto na Amostra FA2 na qual foi detectada a magnetita co-existindo com a ferrita de alumínio e o ferrato de alumínio $\left(\mathrm{AlFeO}_{4}\right)$. A Figura 5 mostra os difratogramas dos catalisadores após a reação e a Tabela 3 mostra as distâncias interplanares calculadas.

Os termogramas de DSC mostrados na Figura 6 e obtidos com os precursores dos catalisadores mostraram, em todos os casos, picos endotérmicos em temperaturas inferiores a $100{ }^{\circ} \mathrm{C}$, atribuídos à perda de materiais voláteis. Isto foi confirmado pelos experimentos de TG (Figura 7), que mostraram uma perda de massa nesta região. A temperaturas superiores a $200{ }^{\circ} \mathrm{C}$, foram observados diferentes perfis de DSC, em função da natureza da amostra. A curva do material sem dopante (Amostra F) apresentou um pico exotérmico a 454 ${ }^{\circ} \mathrm{C}$, devido à transição do (hidr)óxido de ferro para formar hematita ${ }^{38}$. A amostra da alumina pura apresentou um pico endotérmico a 270 ${ }^{\circ} \mathrm{C}$, atribuído ao processo de desidratação do hidróxido de alumínio $(\mathrm{AlOOH})$ para formar óxido de alumínio $\left(\gamma-\mathrm{Al}_{2} \mathrm{O}_{3}\right)^{39}$. A presença de 
Tabela 2. Distâncias interplanares (d) dos catalisadores novos. Amostra A: alumina; Amostra F: óxido de ferro; Amostras FA1 e FA2: hematita contendo alumínio e ferrita de alumínio, respectivamente

\begin{tabular}{|c|c|c|c|c|c|c|}
\hline \multicolumn{7}{|c|}{ Distância interplanar (d) } \\
\hline Ficha & Ficha & Ficha & \multirow{2}{*}{\multicolumn{4}{|c|}{ Amostras }} \\
\hline № 13534 & № 49-1657 & № 29-0063 & & & & \\
\hline & & & & & & \\
\hline Hematita & Ferrita de alumínio & $\gamma$-alumina & $\mathrm{A}$ & FA2 & $\mathrm{F}$ & FA1 \\
\hline 3,710 & - & 4,53 & - & 3,71 & 3,71 & 3,71 \\
\hline 3,662 & 3,67 & - & - & 2,90 & - & - \\
\hline 2,690 & 2,62 & 2,80 & 2,69 & 2,68 & 2,70 & \\
\hline 2,510 & 2,56 & 2,39 & - & 2,56 & 2,54 & 2,51 \\
\hline 2,201 & 2,49 & 2,28 & 2,27 & 2,49 & 2,21 & 2,20 \\
\hline 1,834 & - & 1,98 & - & 1,84 & 1,84 & 1,84 \\
\hline 1,690 & - & 1,53 & 1,51 & 1,71 & 1,69 & 1,69 \\
\hline \multirow[t]{2}{*}{1,484} & - & 1,40 & 1,39 & 1,61 & 1,49 & 1,49 \\
\hline & & & & & 1,45 & 1,45 \\
\hline
\end{tabular}

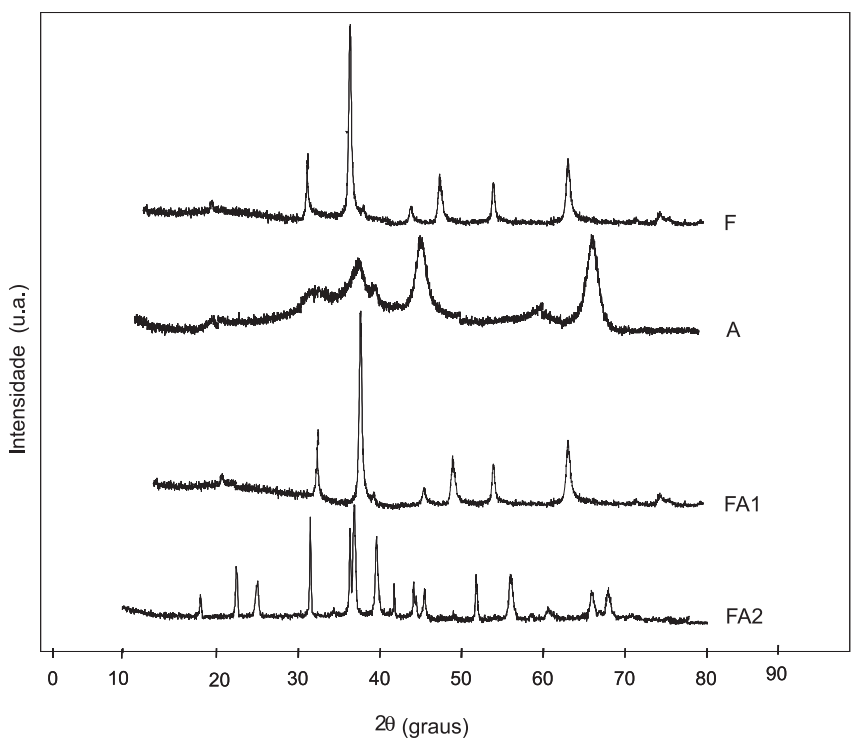

Figura 5 Difratogramas de raios $X$ dos catalisadores usados na reação de desidrogenação do etilbenzeno. Amostra A: alumina; Amostra F: óxido de ferro; Amostras FA1 e FA2: precursores de hematita contendo alumínio e ferrita de alumínio, respectivamente alumínio provocou mudanças no perfil da curva térmica, quando comparada à do (hidr)óxido de ferro. Na curva da Amostra FA1 o pico exotérmico, característico da hematita foi deslocado para temperaturas mais baixas; observou-se um outro pico endotérmico a $270{ }^{\circ} \mathrm{C}$, coincidente com o pico endotérmico da curva da alumina, sugerindo a formação da $\gamma$-alumina nestas amostras. Isto foi confirmado pelos experimentos de TG, cuja curva apresentou perda de massa a temperaturas inferiores a $520^{\circ} \mathrm{C}$, caracterizando essas transições de fases. Esses resultados indicam que a presença do alumínio facilitou a formação da hematita e sugerem a formação da alumina, co-existindo com a hematita. Entretanto, esse composto pode estar formando uma fase cristalina em quantidade insuficiente para ser identificada por difração de raios X, ou, ainda, estar presente como uma fase amorfa, ou formando cristais suficientemente pequenos, impedindo a sua detecção por esta técnica.

O perfil de DSC da Amostra FA2 mostrou um pico próximo a $130{ }^{\circ} \mathrm{C}$, atribuído a perda de água de hidratação ${ }^{40}$. O pico exotérmico, observado a $350{ }^{\circ} \mathrm{C}$ pode ser relacionado à formação da ferrita de alumínio, o que foi confirmado pelo difratograma de raios $\mathrm{X}$ do precursor aquecido a $350{ }^{\circ} \mathrm{C}$, que apresentou picos característicos deste composto.

Os resultados das medidas de área superficial específica dos catalisadores novos e usados são mostrados na Tabela 4. A alumina apresentou um valor de área típico da $\gamma$-alumina ${ }^{35}$. Nos materiais

Tabela 3. Distâncias interplanares (d) dos catalisadores usados. Amostra A: alumina; Amostra F: óxido de ferro; Amostras FA1 e FA2: hematita contendo alumínio e ferrita de alumínio, respectivamente

\begin{tabular}{|c|c|c|c|c|c|c|c|}
\hline \multicolumn{8}{|c|}{ Distância interplanar (d) } \\
\hline Ficha & Ficha & Ficha & Ficha & \multirow{3}{*}{\multicolumn{4}{|c|}{ Amostras }} \\
\hline № $88-0315$ & № $29-0063$ & № $49-1657$ & № $30-0024$ & & & & \\
\hline 2000 JCPDS & 2000 JCPDS & 2000 JCPDS & 2000 JCPDS & & & & \\
\hline Magnetita & $\gamma$-alumina & Ferrita de alumínio & Ferrato de potássio & A & $\mathrm{F}$ & FA1 & FA2 \\
\hline 4,850 & 4,53 & - & 4,64 & - & 4,79 & 4,79 & 4,79 \\
\hline 2,966 & - & 3,67 & 2,84 & - & 2,95 & 2,96 & 3,61 \\
\hline 2,530 & 2,80 & 2,62 & 2,32 & - & 2,49 & 2,50 & 2,68 \\
\hline 2,096 & 2,39 & 2,56 & 2,01 & 2,69 & 2,09 & 2,08 & 2,09 \\
\hline 1,712 & 2,28 & 2,49 & 1,85 & - & 1,71 & 1,71 & 1,84 \\
\hline 1,614 & 1,98 & - & 1,64 & 2,27 & 1,61 & 1,60 & 1,73 \\
\hline 1,483 & 1,53 & - & 1,55 & - & 1,45 & 1,44 & 1,48 \\
\hline 1,327 & 1,40 & - & 1,51 & 1,59 & 1,32 & 1,30 & 1,32 \\
\hline 1,211 & - & - & - & 1,39 & 1,20 & - & - \\
\hline
\end{tabular}




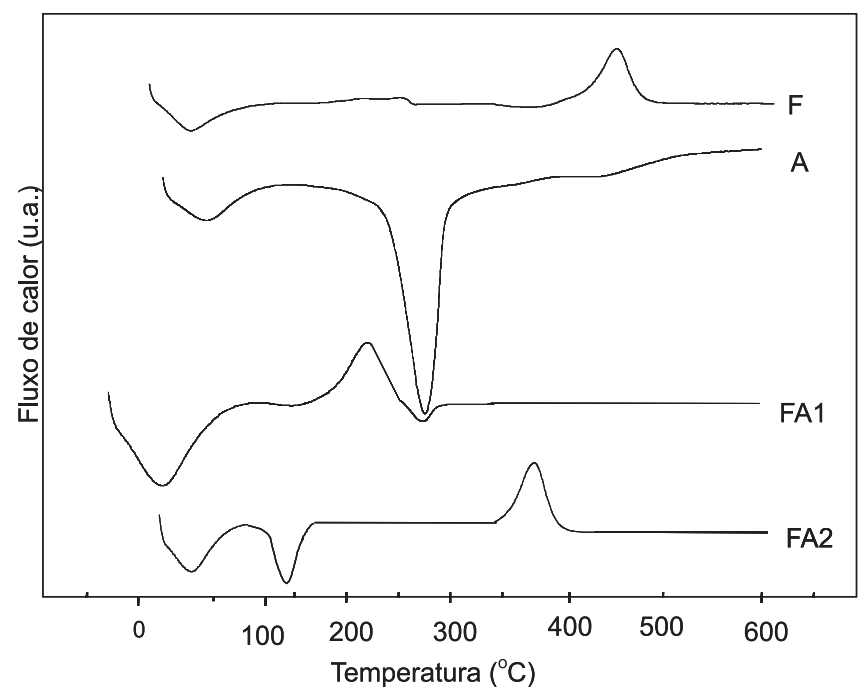

Figura 6. Curvas de calorimetria diferencial de varredura (DSC) obtidas com os precursores dos catalisadores, em atmosfera de nitrogênio. Amostra A: hidróxido de alumino; Amostra F: hidróxido de ferro; Amostras FAl e FA2: precursores de hematita contendo alumínio e ferrita de alumínio, respectivamente

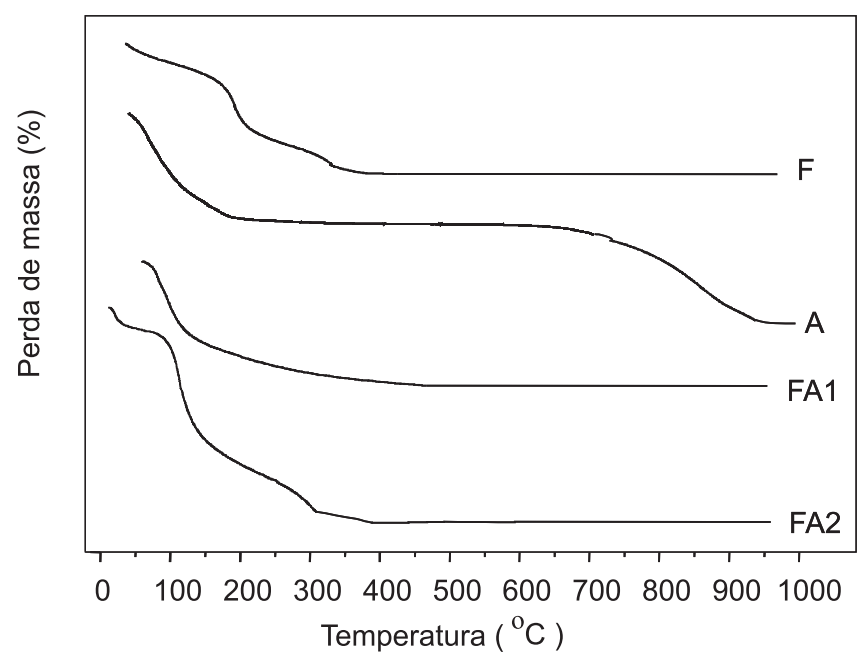

Figura 7. Curvas de termogravimetria (TG) obtidas com os precursores dos catalisadores, em atmosfera de nitrogênio. Amostra A: hidróxido de alumínio; Amostra F: hidróxido de ferro; Amostras FA1 e FA2: precursores de hematita contendo alumínio e ferrita de alumínio, respectivamente

contendo ferro, a presença de alumínio gerou sólidos com áreas mais elevadas quando comparadas com a da amostra isenta deste metal. Este efeito é atribuído à ligação Al-O que, sendo mais forte que a ligação $\mathrm{Fe}-\mathrm{O}$, gera sólidos mais inertes dificultando a mobilidade das espécies para migrar e sinterizar. Além disso, o alumínio pode gerar tensões na rede do óxido de ferro deslocando o equilíbrio na formação de partículas menores, uma vez que a razão tensão/superfície é diminuída ${ }^{41}$. O alumínio pode também atuar como espaçador, na superfície do sólido, criando uma barreira entre as partículas de óxido de ferro e impedindo-as de sinterizar, como se observou em catalisadores da síntese da amônia ${ }^{42}$. É conhecido que, em amostras naturais e sintetizadas em laboratório, o alumínio tem a tendência a migrar para a superfície da hematita ${ }^{43}$. Após o teste catalítico, as áre- as de todos os materiais diminuíram, indicando que a transformação de fase, que ocorreu durante o teste catalítico, foi acompanhada da coalescência de partículas e de poros. Entretanto, a área do sólido com alumínio é ainda mais alta que a hematita, mostrando a ação anti-sinterizante do alumínio, nos catalisadores usados.

Tabela 4. Área superficial específica dos catalisadores novos $\left(\mathrm{S}_{\mathrm{g}}\right)$ e usados $\left(\mathrm{S}_{\mathrm{g}}^{*}\right)$ na reação de desidrogenação do etilbenzeno. Amostra A: alumina; Amostra F: óxido de ferro; Amostras FA1 e FA2: hematita contendo alumínio e ferrita de alumínio, respectivamente

\begin{tabular}{ccc}
\hline Amostra & $\mathrm{S}_{\mathrm{g}}\left(\mathrm{m}^{2} / \mathrm{g}\right)$ & $\mathrm{S}_{\mathrm{g}}^{*}\left(\mathrm{~m}^{2} / \mathrm{g}\right)$ \\
\hline F & 17 & 11 \\
A & 190 & 123 \\
FA1 & 76 & 53 \\
FA2 & 67 & 19 \\
\hline
\end{tabular}

Os perfis de redução termoprogramada dos catalisadores contendo ferro apresentaram perfis similares, com um pico a baixas temperaturas (em torno de $400{ }^{\circ} \mathrm{C}$ ) devido à formação da magnetita e outro, a valores mais elevados (cerca de $740^{\circ} \mathrm{C}$ ), atribuído à produção de ferro metálico ${ }^{44}$. A presença de alumínio deslocou o pico de formação da magnetita e do ferro metálico para temperaturas mais altas, indicando que este metal dificulta a redução do material para formar magnetita ou ferro metálico. Estes resultados indicam que o alumínio estabiliza o estado de oxidação +3 do ferro, altamente seletivo ao estireno, evitando a destruição da fase ativa do catalisador ${ }^{9}$. Como era de se esperar, a curva de TPR da alumina pura não mostrou picos de redução.

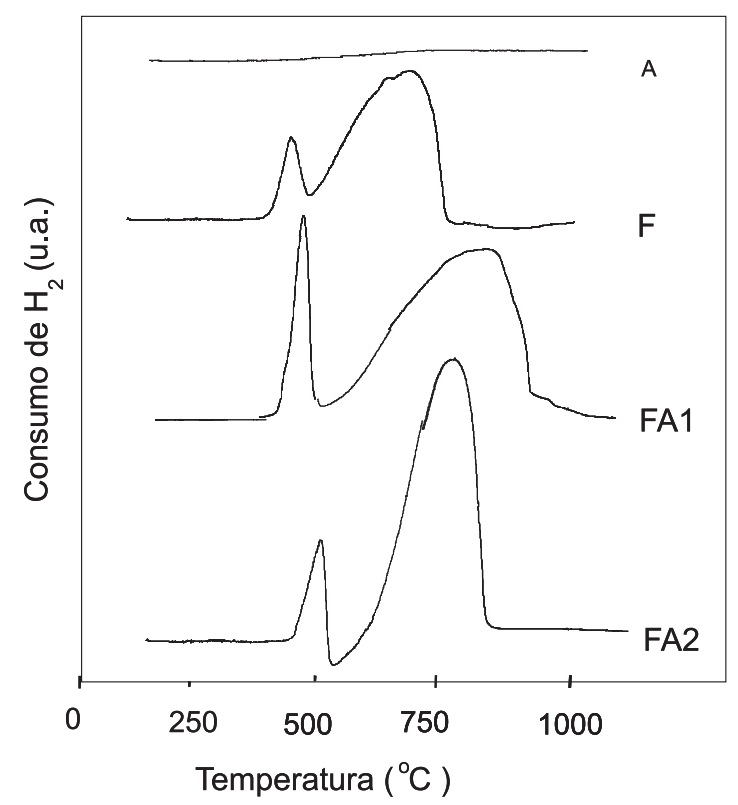

Figura 8. Perfil de redução termoprogramada dos catalisadores. Amostra F: óxido de ferro; Amostra A: alumina. Amostras FA1 e FA2: hematita contendo alumínio e ferrita de alumínio, respectivamente

A Tabela 5 mostra os resultados de atividade e seletividade catalítica das amostras. A definição de atividade, utilizada neste trabalho, considera o número de moles de etilbenzeno que reagem, por unidade de tempo, por número de moles de etilbenzeno alimentados, por grama de catalisador. A definição de seletividade, expressa em percentagem, corresponde à razão entre o número de moles de 
etilbenzeno que foi convertido a estireno e o número de moles totais de estireno que foram convertidos multiplicado por um fator 100 . Todos os catalisadores foram ativos na desidrogenação do etilbenzeno, sendo a alumina o que apresentou a mais baixa atividade e seletividade. Isto pode ser atribuído à presença de vapor, que compete com o etilbenzeno pelos sítios ativos; no caso dos compostos de ferro, o vapor atua protegendo o catalisador contra a destruição da fase ativa, re-oxidando os sítios que eventualmente tenham sido reduzidos $^{45}$. Os compostos de alumínio e ferro foram cataliticamente mais ativos que a hematita, sendo a Amostra FA1 (hematita contendo alumínio) aquela que apresentou maior atividade e seletividade.

Tabela 5. Atividade (a), atividade por área $\left(\mathrm{a} / \mathrm{S}_{\mathrm{g}}\right)$ e seletividade $(\mathrm{S})$ na desidrogenação do etilbenzeno e razão $\mathrm{Fe}^{+2} / \mathrm{Fe}^{+3}$ dos catalisadores usados. Amostra A: alumina; Amostra F: óxido de ferro; Amostras FA1 e FA2: hematita contendo alumínio e ferrita de alumínio, respectivamente

\begin{tabular}{lcccc}
\hline Amostra & $\begin{array}{c}\text { a x 10 } \\
(\mathrm{mol} / \mathrm{g} . \mathrm{s})\end{array}$ & $\begin{array}{c}\mathrm{a} / \mathrm{Sg} \times 10^{7} \\
\left(\mathrm{~mol} / \mathrm{s} \cdot \mathrm{m}^{2}\right)\end{array}$ & $\mathrm{S}(\%)$ & $\begin{array}{c}\mathrm{Fe}^{+2} / \mathrm{Fe}^{+3} \\
\text { (após teste) }\end{array}$ \\
\hline F & 2,9 & 1,2 & 94,0 & 0,5 \\
A & 0,9 & 0,1 & 44,0 & - \\
FA1 & 8,9 & 3,1 & 96,0 & 0,2 \\
FA2 & 5,1 & 2,5 & 79,0 & 0,4 \\
\hline
\end{tabular}

As atividades por área foram calculada dividindo-se a atividade dos catalisadores pela sua área, após a reação. Estes valores variaram em função da natureza química e das fases presentes nas amostras. Como os catalisadores sob estudo são mássicos, esses valores representam adequadamente as atividades intrínsecas. Nota-se que as atividades intrínsecas das amostras contendo ferro e alumínio (Amostras FA1 e FA2) foram mais elevadas que a do óxido de ferro puro, indicando uma ação estrutural deste metal. Este efeito é mais intenso na Amostra FA1.

A seletividade a estireno é diminuída devido ao alumínio, no caso da Amostra FA2, mas praticamente não é alterada no caso da Amostra FA1, em relação ao óxido de ferro puro (Amostra F). Isto indica a presença de sítios de diferentes naturezas, em cada caso, como consequência das diferentes fases observadas e sugere que a espécie $\mathrm{Fe}^{+}$, no ambiente da hematita (corundum), é cataliticamente mais ativa e mais seletiva que na estrutura da ferrita (espinélio).

Os valores da razão $\mathrm{Fe}(\mathrm{II}) / \mathrm{Fe}$ (III) permaneceram próximos a 0,5 , que é o valor estequiométrico da magnetita, indicando que esta é a fase estável, nas condições da reação.

A partir dos resultados obtidos neste trabalho, pode-se concluir que óxidos de ferro (hematita) contendo alumínio e ferrita de alumínio são catalisadores ativos e seletivos na desidrogenação do etilbenzeno. O primeiro possui maior atividade intrínseca que o segundo, que possui menor área superficial específica. Nestes materiais, o alumínio atua como promotor textural e estrutural. O catalisador mais promissor é aquele à base de hematita, que é o mais seletivo a estireno e que possui maior área superficial específica. Sua atividade é de $8,1 \times 10^{-6} \mathrm{~mol} \mathrm{~s}^{-1} \mathrm{~g}^{-1}$ e sua seletividade é de $96 \%$, que são valores superiores a um catalisador comercial cuja medida experimental, nas mesmas condições de reação que as amostras preparadas, mostrou um valor de atividade de $3,6 \times 10^{-6} \mathrm{~mol} \mathrm{~s}^{-1} \mathrm{~g}^{-1}$ e seletividade de $70 \%$.

\section{CONCLUSÕES}

Compostos de ferro e alumínio, obtidos como hematita dopada com alumínio ou como ferritas de alumínio, são catalisadores ativos e seletivos na desidrogenação do etilbenzeno em presença de vapor d'água. Esses sólidos são cataliticamente mais ativos que a hematita e são mais resistentes à desativação por redução da fase ativa (hematita). O catalisador à base de ferrita de alumínio é menos seletivo do que aquele à base de hematita e alumínio e isto foi atribuído a sítios de diferentes naturezas nos dois casos. O alumínio atua como promotor textural e estrutural nos dois catalisadores e a maior atividade intrínseca foi apresentada pela hematita contendo alumínio. Este catalisador é o mais promissor, pois é o mais ativo e seletivo e apresenta o valor mais elevado de área superficial específica. Este sólido apresenta, ainda, como vantagens o fato de não causar danos ao homem e ao meio ambiente, podendo ser facilmente manuseado e descartado, e de não conter potássio, o que deverá minimizar a sua desativação.

\section{AGRADECIMENTOS}

Os autores agradecem o suporte financeiro do PADCT/FINEP e do CNPq. A. C. Oliveira agradece ao CNPq pela bolsa de estudos de mestrado. Os autores também agradecem a ajuda de S. T. Brandão e M. L. Correa nos experimentos de difração de raios X.

\section{REFERÊNCIAS}

1. Lee, E. H.; Catal. Rev. Sci. Eng. 1963, 8, 285.

2. Shreve, M. R.; Brink, A. J.; Indústrias dos Processos Químicos, Guanabara Koogan S. A.: Rio de Janeiro, 1977, vol. 1, p. 140.

3. Zhyzenevskiv, V.; Tsybukiv, R.; Gumenetskiy, K.; React. Kinet. Catal. Lett. 2000, 2, 71.

4. Mimura, N.; Saito, M.; Catal. Today 2000, 55, 173.

5. Li, W. Y.; Lettman, C.; Maier, W. F.; Catal. Lett. 2000, 69, 181.

6. Coutler, K.; Goodman, D. W.; Moore, R. G.; Catal. Lett. 1995, 31, 1.

7. Oh, S. W.; Ayala, N.; Broadbelt, L. J.; Catal. Today 2000, 55, 161.

8. Adieggo, W. P.; Boger, T.; Liu, W.; Catal. Today 2001, 69, 25.

9. Herzog, B. D.; Raso, H. F.; Ind. Eng. Chem. Prod. Res. Dev. 1984, 23, 187.

10. Styles, A. B.; Applied Industrial Catalysis, Leach, B. E., ed.; Academic Press: New York, 1987, p.137.

11. Mihajlova, A.; Andreev, A.; Shopov, D.; Dimitrova, R.; Appl. Catal. 1988, 40, 247.

12. Matsui, J.; Sodesawa, T.; Nozaki, F.; Appl. Catal. 1991, 17, 179.

13. Le Page, J. F.; Courty, P.; Catalyse de Contact. Techinp. 1978, 14, 239.

14. Hirano, T.; Appl. Catal. 1986, 28, 119.

15. Barbosa, M. N.; Dissertação de Mestrado, Universidade Federal da Bahia, Brasil, 1995.

16. Lacorre, P. H.; Hervieu, M.; Raveau, B.; Structural Relationshhip in Closed-Packed $\mathrm{M}_{3} \mathrm{O}_{4}$ and $\mathrm{M}_{5} \mathrm{O}_{8}$ Oxides. Extension to Hexagonal Ferrites, Université de Caen: France, 1984, p. 148.

17. Smith, J.; Wijn, H. P. J.; Ferrites, Wiley: New York, 1959, p. 53.

18. Johnson, D. W. J.; Vogel, E. M.; Ghate, B. B.; Proceedings of the International Conference, Tokio, Japan, 1980.

19. Sreekumar, K.; Mathew, T.; Devassy, B. M.; Rajgopal, R.; Rao, B. S. V.; Appl. Catal., A 2001, 205, 11.

20. Matijévic, E.; Simpson, C. M.; Amin, N.; Arajs, S.; Colloids Surf. 1986, $21,101$.

21. Kunal, B.; Modi, H.; Joshi, H.; J. Mater. Sci. Lett. 1998, 17, 741.

22. Fedecva, V. I.; Voinov, I. D.; Kinet. Catal. 1978, 19, 625.

23. Carvalho, M. F. A.; Tese de Doutorado, Universidade Federal da Bahia, Brasil, 2001.

24. Kirk, R. E.; Othmer, R. F.; Encyclopedia of Chemical Technology, $3^{\mathrm{a}}$ ed., Wiley Interscience: New York, 1984, vol. 15, p. 775.

25. Taylor, R. M.; Schwertmann, V.; Clays Clay Miner. 1980, 28, 267.

26. Carneiro, G. A.; Rangel, M. C.; Catal. Today 2000, 62, 201.

27. Oliveira, A. C.; Valentini, A.; Nobre, P. S. S.; Rangel, M. C.; React. Kinet. Catal. Lett. 2002, 75, 1.

28. Jebarathinam, N. J.; Eswaramoorty, M.; Krishnasamy, V.; Bull. Chem. Soc. Jpn. 1994, 67, 3334.

29. Kruger, H.; J. Chem. Soc. 1982, 11, 227.

30. Hunt, J. P.; Metal Ions in Aqueous Solutions, Benjamin W. A. Inc.: New York, 1965, cap. 6, p. 45

31. Blesa, M. A.; Matijevic, E.; Adv. Colloid Interface Sci. 1989, 29, 173

32. Niquist, R. A.; Kagel, R. O.; Infrared Spectra of Inorganic Compounds, Academic Press: Orland, 1971. 
33. Gallagher, P. K.; Johnson, D. W.; Schrey, F.; Nitti, J. D.; Ceram. Bull. 1973, 52,842 .

34. Mcintyre, J. F.; Foley, R. T.; Brown, B. F.; Appl. Spectrosc. 1982, 36, 128.

35. Mahamad, M.; Barboot, L.; FadeilJasin, I.; Tobia, K.; Thermochim. Acta 1971, 21, 399.

36. Busca, G.; Daturi, M.; Kotur, E.; Olivieri, G.; Willey, R. G. Em Scientific Bases for the Preparation of Heterogenous Catalysts; Delmon, B.; Grange, P.; Jacobs, P.; Poncelet, G., eds.; Elsevier Science Publishers: Amsterdam, 1995, 667.

37. Khopkar, P. M.; Kulkami, J. A.; Daishame, V. S.; Thermochim. Acta 1995, $93,481$.
38. Gadalla, A. M.; Levingston, T. W.; Thermochim. Acta 1989, 133, 101.

39. Hester, R. E.; Pean, R. A.; Inorg. Chem. 1964, 31 ,769.

40. Villacelos, R. G.; Herman, L.; Morales, J.; Tirado, J.; J. Colloid. Interface Sci. 1984, 101, 393

41. Topsoe, H.; Dumestic, J. A.; Boudart, M.; J. Catal. 1978, 28, 477.

42. Nielsen, A.; Bohlbro, H. Em Investigation on Promoted Iron Catalysts for the Synthesis of Ammonia; Ed. Gjllerup Forlag: Copenhagen, 1968, p. 221.

43. Grave, E. D.; J. Magn. Mater. 1988, 72, 141.

44. González, J. C.; González, M. C.; Laborde, M. A.; Moreno, N.; Appl. Catal. 1986, 20, 3

45. Cavani, F.; Trifiro, F.; Appl. Catal. 1995, 133, 219. 